University of New Hampshire

University of New Hampshire Scholars' Repository

$1-2001$

\title{
The Decline in Child Sexual Abuse Cases.
}

Lisa M. Jones

University of New Hampshire - Main Campus, lisa.jones@unh.edu

David Finkelhor

University of New Hampshire - Main Campus, David.Finkelhor@unh.edu

Follow this and additional works at: https://scholars.unh.edu/ccrc

Part of the Criminology and Criminal Justice Commons, Psychology Commons, and the Sociology Commons

\section{Recommended Citation}

Jones, Lisa and Finkelhor, David. The decline in child sexual abuse cases. Juvenile Justice Bulletin NCJ184741 (pgs. 1-12). Washington, DC: US Government Printing Office.

This Article is brought to you for free and open access by the Research Institutes, Centers and Programs at University of New Hampshire Scholars' Repository. It has been accepted for inclusion in Crimes Against Children Research Center by an authorized administrator of University of New Hampshire Scholars' Repository. For more information, please contact Scholarly.Communication@unh.edu. 


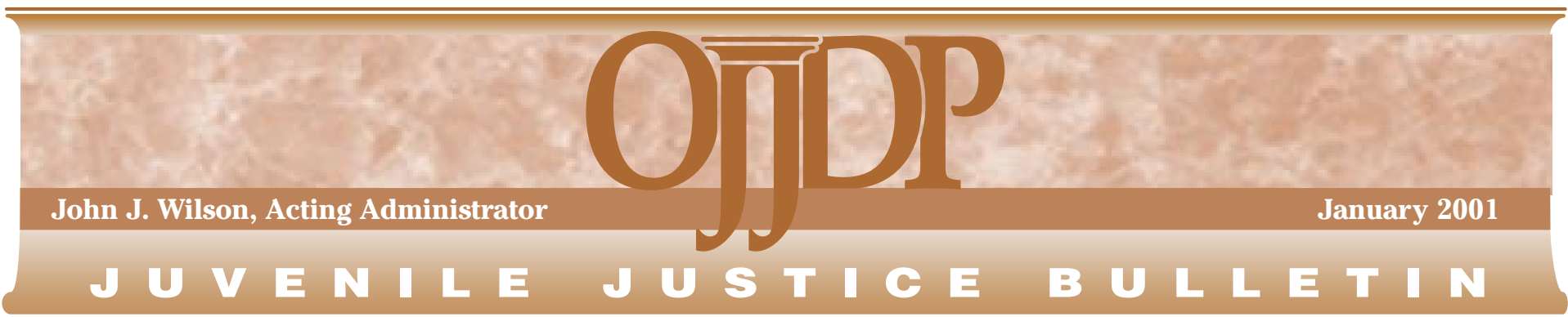

\section{The Decline in Child Sexual Abuse Cases}

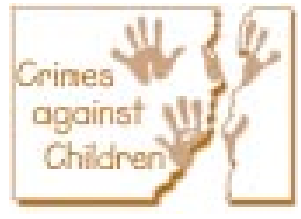

\section{Lisa Jones and David Finkelhor}

The Office of Juvenile Justice and Delinquency Prevention (OJJDP) is committed to improving the justice system's response to crimes against children. OJJDP recognizes that children are at increased risk for crime victimization. Not only are children the victims of many of the same crimes that victimize adults, they are subject to other crimes, like child abuse and neglect, that are specific to childhood. The impact of these crimes on young victims can be devastating, and the violent or sexual victimization of children can often lead to an intergenerational cycle of violence and abuse. The purpose of OJJDP's Crimes Against Children Series is to improve and expand the Nation's efforts to better serve child victims by presenting the latest information about child victimization, including analyses of crime victimization statistics, studies of child victims and their special needs, and descriptions of programs and approaches that address these needs.

Of all crimes against children, sexual abuse has arguably captured the greatest share of attention from child advocates, professionals, policymakers, and the general public. During the 1980's, increasing numbers of victims were identified each year (American Association for the Protection of Children, 1988) and concerns about this crime intensified. However, a dramatic shift in child sexual abuse trends has occurred. Data from child protective services (CPS) agencies across the country indicate that the increases of the 1980's were followed by an extensive period of marked declines in the 1990's. Unfortunately, little effort has been expended to uncover the reasons why fewer cases of child sexual abuse have been identified each year. The decline in child sexual abuse cases is being highlighted as a part of OJJDP's Crimes Against Children Series to illustrate the importance of tracking and investigating trends in child victimization. This Bulletin uses data from the National Child Abuse and Neglect Data System (NCANDS) and the Annual Fifty State Survey conducted by Prevent Child Abuse America to present evidence about the decline in reported and substantiated child sexual abuse cases since the early 1990's. Several explanations for the decline are considered, and corresponding policy implications are discussed.

\section{From the Administrator}

While recent reductions in juvenile crime-offenses by youth-have generated some media coverage, the decline in child sexual abuseoffenses against youth-has received far less attention. Yet, we know that the sexual exploitation of children can have significant impact on its victims and even contribute to an intergenerational cycle of violence and abuse.

Child protective services agencies report that the increases in child sexual abuse that marked the 1980's were followed by a protracted period of substantial declines in the 1990's. From 1992 to 1998, for example, substantiated cases of child sexual abuse decreased by nearly a third.

A critical, and largely unexamined, question is "why?" Using data from the National Child Abuse and Neglect Data System and other sources, this Bulletin describes declines in both reported and substantiated child sexual abuse from the early 1990's and identifies possible factors influencing those declines. The policy implications suggested by the decrease in child sexual abuse are also explored.

Further research is needed to better understand the reasons why child sexual abuse has declined. This Bulletin, however, will enhance our knowledge of this noteworthy trend and its potential causes and effects.

John J. Wilson

Acting Administrator 


\section{Highlights}

The analysis of child sexual abuse cases presented in this Bulletin reveals the following:

- Substantiated cases of child sexual abuse decreased from a national estimated peak of 149,800 cases in 1992 to 103,600 cases in 1998, a decline of 31 percent.

- A decline in substantiated cases has occurred in the majority of States, with no clear regional pattern. Out of 47 States with complete data, 36 recorded a decline of more than 30 percent since their peak year. The average decline for all States was 37 percent.

- For most States, the decline was gradual, rather than abrupt, and occurred over several years.

- Although cases of other types of child maltreatment have also declined in recent years, the decrease in child sexual abuse cases has been more marked. Substantiated cases of physical abuse declined 16 percent from a 1995 peak, compared with a 31-percent decline in child sexual abuse cases.

- In addition to the decline in the number of substantiated cases, child sexual abuse reports also decreased from an estimated 429,000 in 1991 to 315,400 in 1998 , a 26 -percent decline.

- Possible explanations for the decline include a real underlying decline in the incidence of child sexual abuse or changes in attitudes, policies, and standards that have reduced the amount of child sexual abuse being reported and substantiated. It is possible that both of these processes are affecting trends in child sexual abuse.

\section{Substantiated Sexual Abuse}

After a 15-year increase (1977-92), national data show that substantiated cases of child sexual abuse have been decreasing since about 1992. Summary data from NCANDS indicate that cases of substantiated child sexual abuse reached an estimated peak of 149,800 in 1992 , followed by declines of 2 to 11 percent each year through 1998, the last year for which data are available (figure 1). In 1998, estimated cases of child sexual abuse reached a low of approximately $103,600 .{ }^{1}$ This is a total decline of 31 percent in identified child sexual abuse cases over a 6 -year period.

Figure 1: Substantiated Cases of Child Sexual Abuse, 1990-98

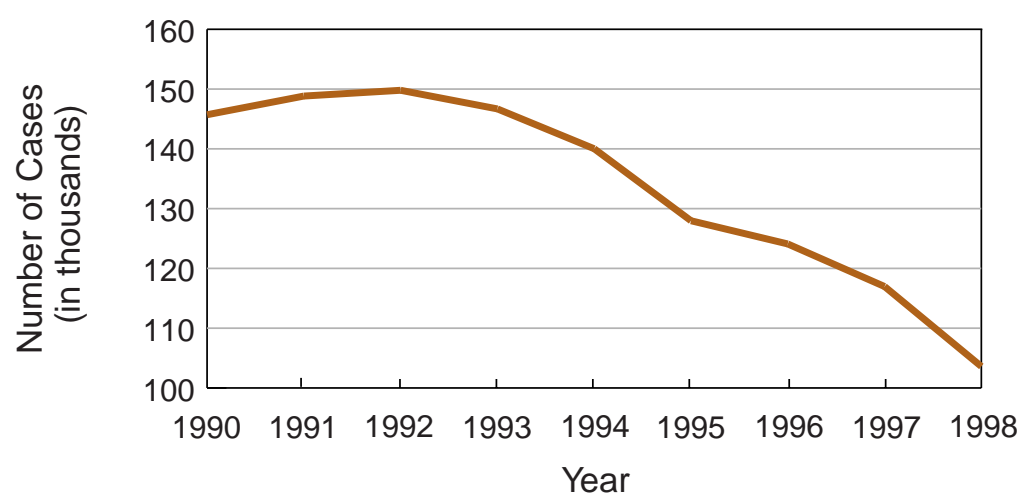

Note: Extrapolated to the U.S. child population.

Source: Authors' analyses of 1990-98 data (U.S. Department of Health and Human Services, 1992-2000).

\section{Figure 2: States With Major Increases and Decreases in Substantiated Cases of Child Sexual Abuse Within Four 2-Year Periods}

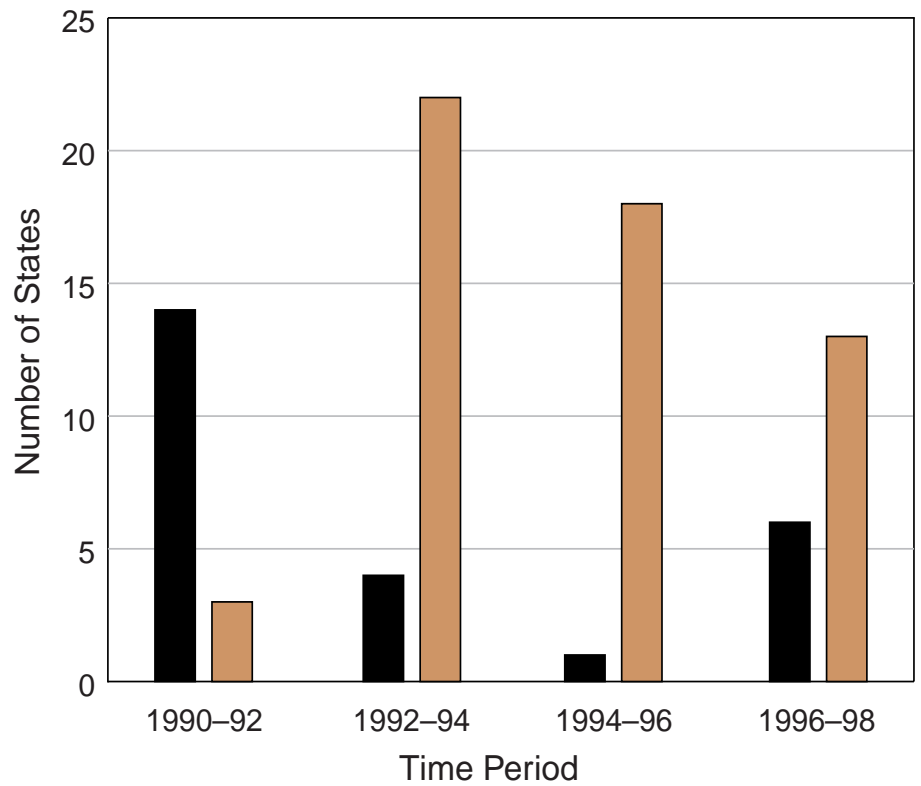

Major* Increases in Sexual Abuse Substantiations

Major* Decreases in Sexual Abuse Substantiations

* Twenty percent or more.

Source: Authors' analyses of 1990-98 data (U.S. Department of Health and Human Services, 1992-2000).

The trend is not universal, but it is affecting more and more States. ${ }^{2}$ Between 1990 and 1992, 14 States experienced increases of 20 percent or more in substantiated cases of child sexual abuse. Only three States recorded notable declines during the same period (figure 2). Between 1992 and 1994, however, 22 States experienced declines of
20 percent or more in substantiated cases of child sexual abuse. Between 1994 and 1996, 18 States saw further declines of this magnitude. Meanwhile, the number of States recording increases of 20 percent or more had fallen to one. From 1996 to 1998, 13 States recorded substantial declines, while 6 recorded substantial increases. Over the 
Figure 3: Declines in Substantiated Cases of Child Sexual Abuse, by State

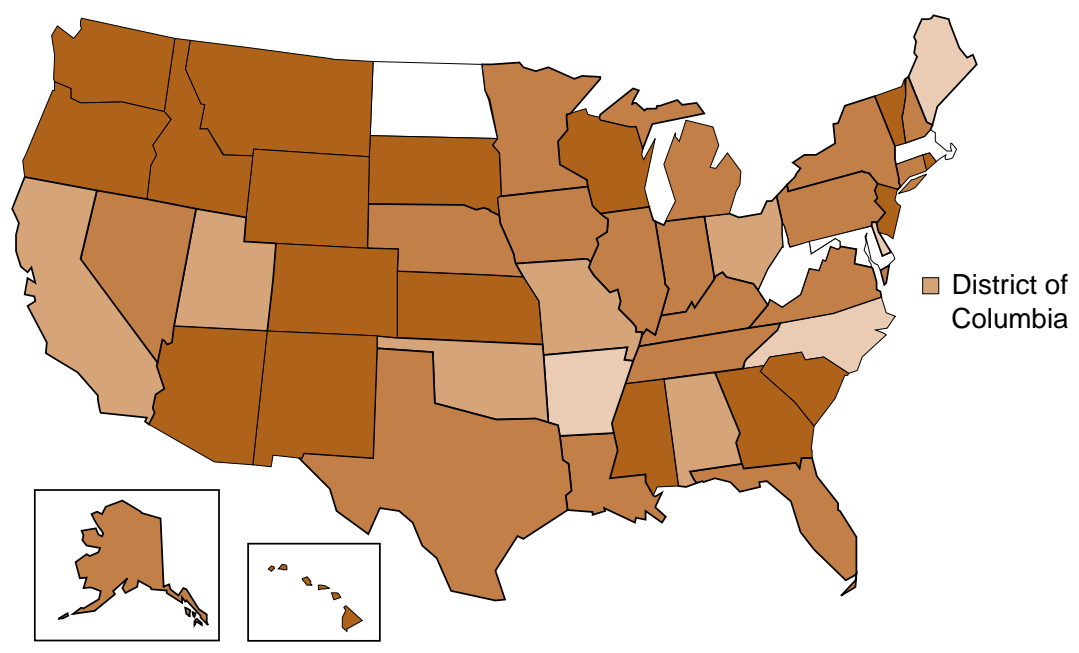
More than $45 \%(18)$
$31-45 \%(18)$
$16-30 \%(7)$
Missing data (4)

Note: Total State decline defined by calculating change from each State's peak year through 1998.

Source: Authors' analyses of 1990-98 data (U.S. Department of Health and Human Services, 1992-2000). whole period (1992-98), the majority of States (36 out of 47 with complete data) experienced a total decline of more than 30 percent in substantiated cases of child sexual abuse from their peak year to the year 1998 (figure 3). There is no clear regional pattern to these declines, which have occurred across all areas of the country.
These significant declines contrast with the period of the 1980's, when most States experienced 10-percent annual increases in child sexual abuse caseloads. Even as recently as 1991-92, 18 States experienced these 10percent increases. This trend is reflected in the Third National Incidence Study of Child Abuse and Neglect (NIS-3), which reported a 125-percent rise in the incidence of child sexual abuse from 1986 to 1993 (Sedlak and
Figure 4: Child Sexual Abuse Reports, 1987-98

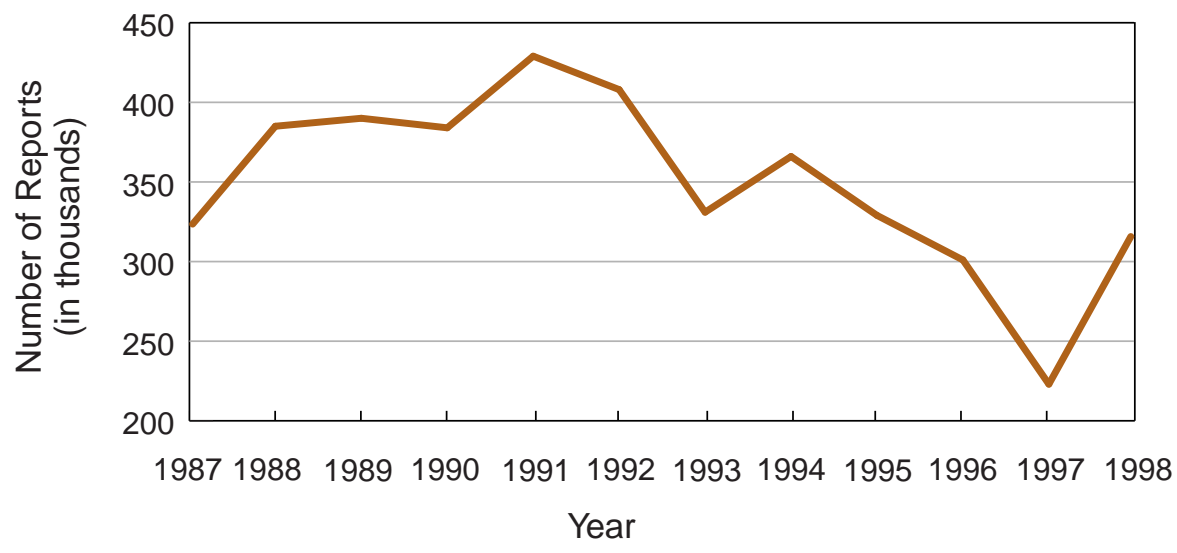

Source: Authors' analyses of 1987-98 data (Prevent Child Abuse America, 1987-98).
Broadhurst, 1996). This study identified a nationally representative sample of counties across the country and surveyed professionals in schools, daycare centers, hospitals, police departments, and CPS offices about cases of observed child maltreatment. However, the NIS series, which measured incidence at only three time points (1980, 1986, and 1993), does not offer information recent enough to detect the decline in cases that had only begun to gather steam in 1993.

\section{Reports of Child Sexual Abuse}

Data presented by Prevent Child Abuse America in their Annual Fifty State Survey indicate that reports of child sexual abuse appear to be decreasing at a pace equal to, if not greater than, that of the decline in substantiated cases. The Annual Fifty State Survey (Wang and Daro, 1998) estimated that there were 223,000 reports of child sexual abuse in 1997 (figure 4). This is an overall decline of 48 percent since 1991. The most recent estimated numbers from 1998 (Wang and Harding, 1999) show an increase in reports over 1997 but still represent an overall decline of 26 percent since the 1991 peak. $^{3}$

Comparing trends in child sexual abuse reports with trends in substantiated cases is important to a better understanding of the causes of the decline in child sexual abuse. The decline in reports suggests that the drop in substantiated cases is at least partly the result of fewer reports of child sexual abuse reaching CPS agencies. Therefore, any complete understanding of the causes must include a consideration that either there are fewer actual incidents of child sexual abuse available to be reported or changes have occurred in reporting behavior for this crime.

\section{Decline in Child Sexual Abuse Greater Than Decline in Physical Abuse or Neglect}

The decline in reported and substantiated cases of child sexual abuse does not appear to be just an extension of a general declining trend in overall child maltreatment. The estimated total reports of child maltreatment increased dramatically in the 1980's and, though the rate of increase has slowed, the numbers have continued to climb through the 1990's. ${ }^{4}$ 
However, despite increasing numbers of reports during the 1990's, the percentage of reports that were child sexual abuse allegations decreased. Sexual abuse reports dropped from 16 percent of all child maltreatment reports in 1986 to an average of 8 percent of reports from 1996 to 1998.

According to NCANDS data, there has been a slight decline ( 9 percent) in substantiated cases of general maltreatment during the 1990's. Overall maltreatment reached an estimated peak of 1,206,500 in 1992 and dropped to a low of 1,093,600 in 1998. The decline in child sexual abuse appears to account for most of this decline. Neglect cases, which make up the greatest proportion of CPS cases, have declined an estimated 5 percent from a peak in 1994. A somewhat more noticeable decline has occurred with physical abuse cases, but this decline is half the size and more recent than the decline in child sexual abuse cases (figure 5). The peak in substantiated cases of physical abuse occurred in 1995, and there was a 16-percent decline over the next 3 years. The largest proportion of that decline (13 percent) occurred from 1997 to 1998. In comparison, the number of substantiated cases of child sexual

\section{Figure 6: Comparison of Trends in Substantiated Cases of Child Physical and Sexual Abuse, 1992-98, by State}

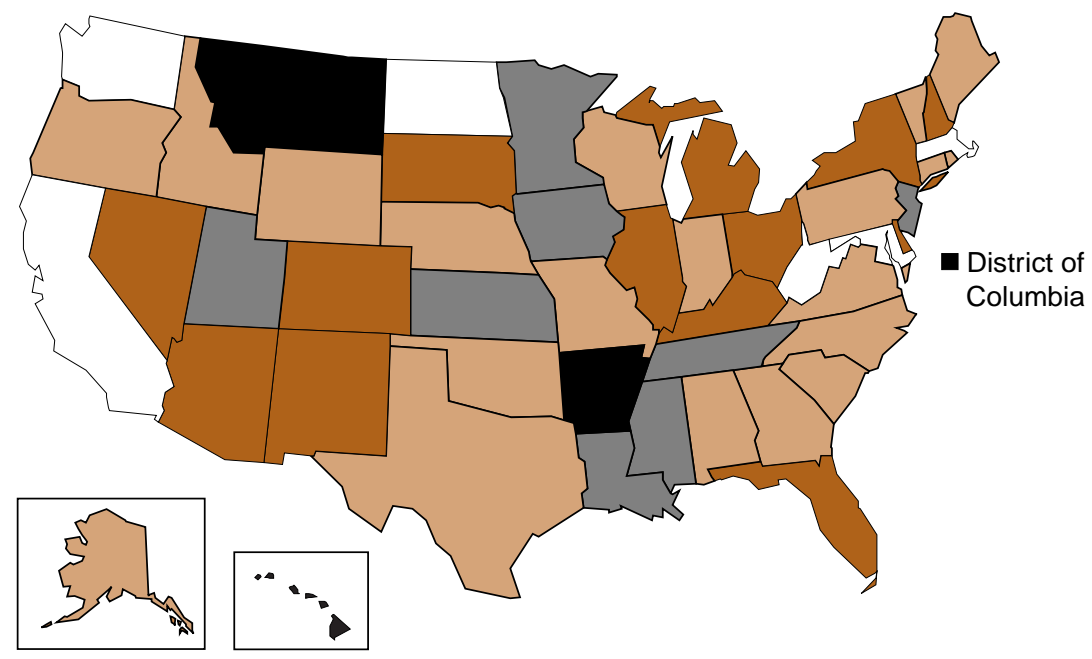

Sexual abuse decline more than $20 \%$ greater (13)

Sexual abuse decline less than $20 \%$ greater (20)

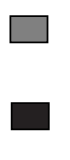

Physical abuse decline less than $20 \%$ greater (8)

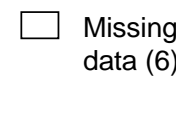

Physical abuse decline more than $20 \%$ greater (4)

Source: Authors' analyses of 1990-98 data (U.S. Department of Health and Human Services, 1992-2000).
Across the country, an overwhelming majority of States are recording more dramatic declines in child sexual abuse than in other types of maltreatment. Thirty-three States experienced greater declines in substantiated cases of child sexual abuse than in substantiated cases of physical abuse. Thirteen of these States experienced declines in child sexual abuse that were much greater (more than 20 percent greater) than their declines in physical abuse (figure 6). Only four States, on the other hand, recorded much greater declines in their physical abuse cases. Just as the increase in child sexual abuse cases in the 1980's outpaced that of physical abuse cases, so their decline in the 1990's appears to be singularly dramatic as well.

\section{Possible Reasons for the Decline}

Several factors may explain the decline in child sexual abuse cases. These factors generally can be divided into two categories: (1) a real decline in child sexual abuse or (2) changes in attitudes, policies, or standards that result in fewer reports and substantiations. Figure 7 illustrates some of the factors that could reduce the number of reports and substantiated cases of child sexual abuse. Although these are alternative explanations of the trend, they are not mutually exclusive. Any or all of these processes could be occurring simultaneously. 


\section{Decline in True Incidence}

The most optimistic explanation is that incidents of child sexual abuse are decreasing. A great deal of public awareness of the problem has developed in the past 20 years. Prevention programs that target children are widespread (Finkelhor and Dziuba-Leatherman, 1995). A large number of offenders have been incarcerated (Beck et al., 1993). Many treatment programs have been directed toward offenders to prevent them from reoffending (Freeman-Longo et al., 1994), and laws have been passed in many States to improve the monitor- ing of sex offenders in the community (Finn, 1997). All of these efforts could have the cumulative effect of reducing incidents of child sexual abuse.

Evidence that child sexual abuse has actually declined appears to be supported by parallel declines in various social problem indicators with possibly similar etiological sources. For example, national rates of female victimization by intimate partners, rape victimization, and overall violent crime have been declining at levels comparable to the child sexual abuse rate over a similar period of time (figure 8). There has been a 21-percent

\section{Figure 7: Possible Factors Influencing the Decline in Substantiated Cases of Child Sexual Abuse}
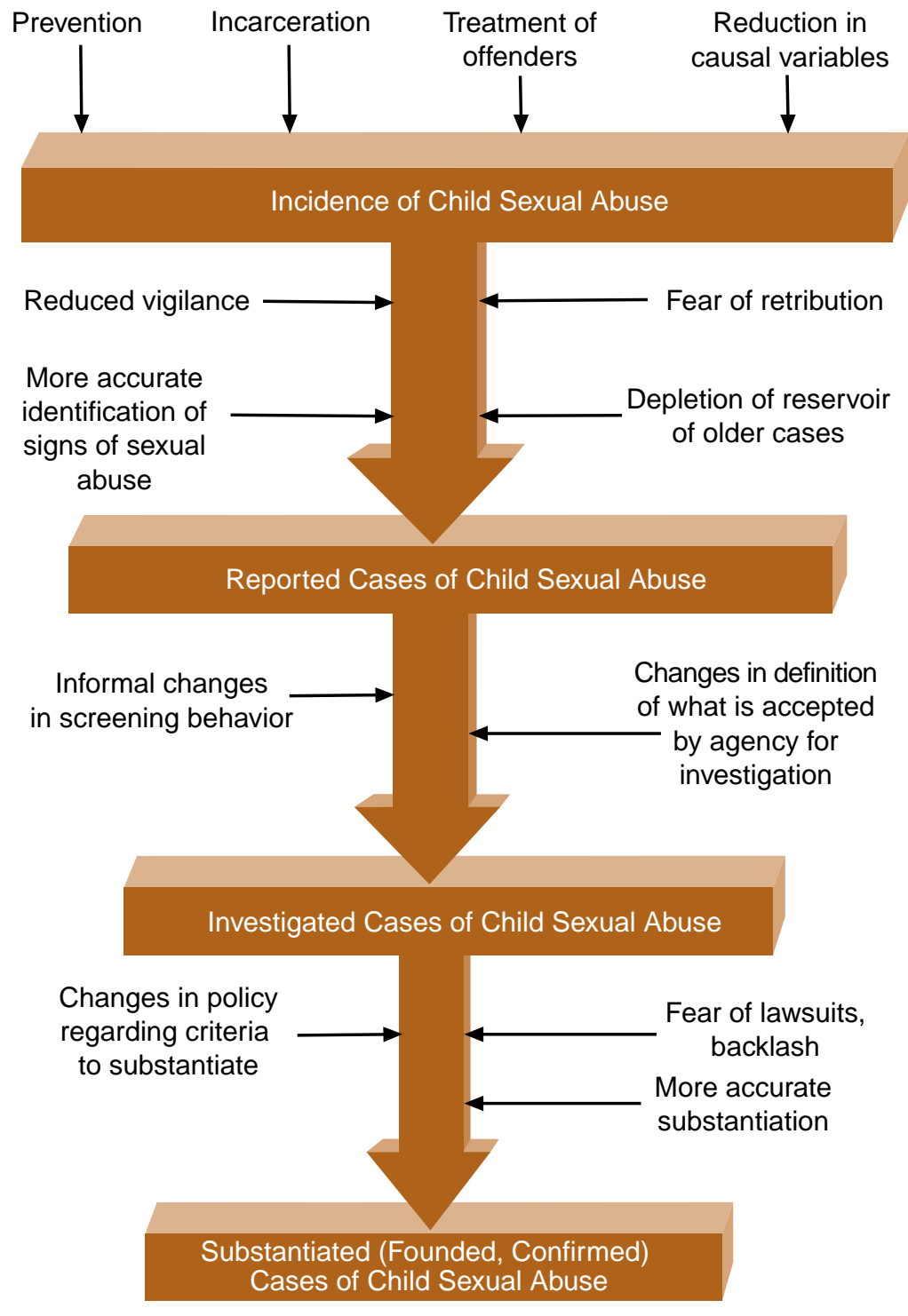

decline in the rate of female victimization by intimate partners since 1993, a 60 -percent decline in the rate of forcible rape since 1991, and a 30-percent decline in the rate of overall violent crime since 1994. Each of these declines is likely to represent an actual decrease in incidence because they are based on the National Crime Victimization Survey (NCVS), a direct self-report survey. Factors that may be responsible for the declines in these crimes could also be responsible for the declines in child sexual abuse.

Trends in child sexual abuse could be expected to parallel trends in intimate partner violence in particular. Both crimes involve primarily female victims and male perpetrators and both crimes have been obscured because victims are embarrassed and the crimes often occur in private locations. The two problems also share similar advocacy histories. Both child sexual abuse and partner violence received similar national attention during the 1980's through widespread public awareness programs, increased prevention programs, a growth in the variety of treatment options for offenders, and intensified efforts to report, prosecute, and incarcerate offenders.

There may also be a connection between the well-documented declines in the rates of teen births (down 21 percent since 1991) and child poverty (down 18 percent since 1993) and the decline in child sexual abuse. Child sexual abuse has been shown to be a significant risk factor for, and sometimes a direct cause of, teen pregnancy (Boyer and Fine, 1992; Elders and Albert, 1998), so the decline in teen births could be seen as consistent with a decline in sexual abuse. Still, teen births could also decline for reasons completely unrelated to sexual abuse. As for poverty, economic variables typically have been more closely associated with rates of physical abuse and neglect than with rates of sexual abuse. Nonetheless, because it alleviates despair, reduces the free time of potential perpetrators, and gives them a stake in conformity, improvement in a family's economic stability may offer children some protection from sexual abuse victimization as well. The fact that other child welfare indicators show so much improvement makes the possibility of a real decline in child sexual abuse seem more plausible.

However, while at the national level the trends in these indicators appear similar 
Figure 8: Comparison of the Decline in Substantiated Cases of Child Sexual Abuse With Declines in Rates of Female Victimization by Intimate Partners, Total Violent Crime, Rape Victimization, Child Poverty, and Teen Births

Extrapolated Child Sexual Abuse Substantiations*

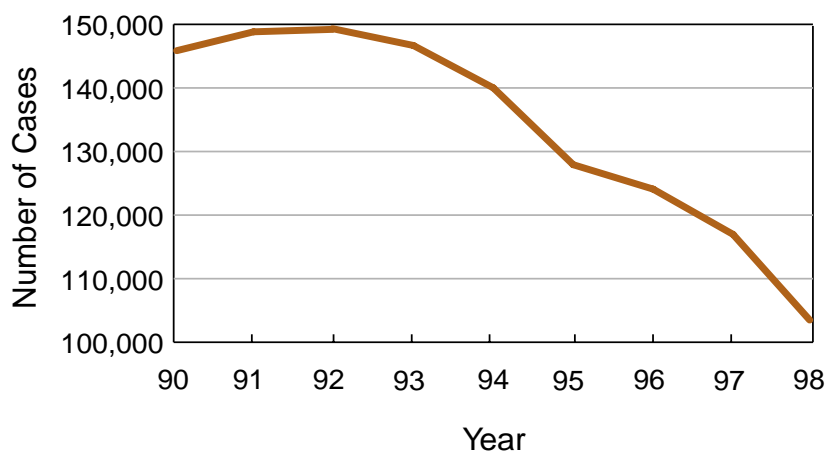

Total Violent Crime

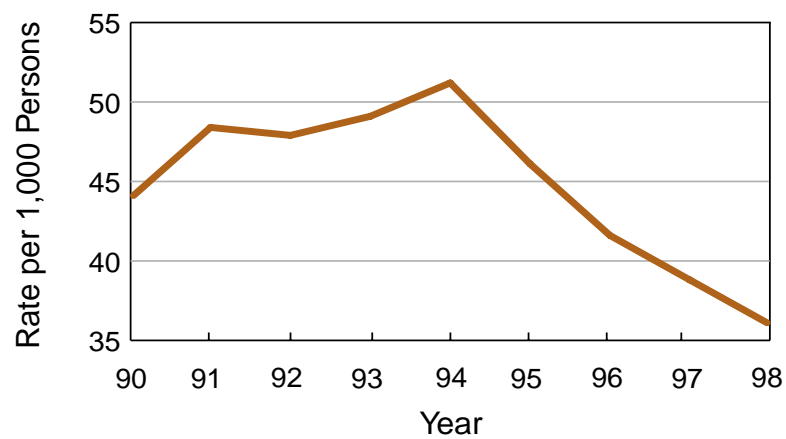

Children in Poverty§

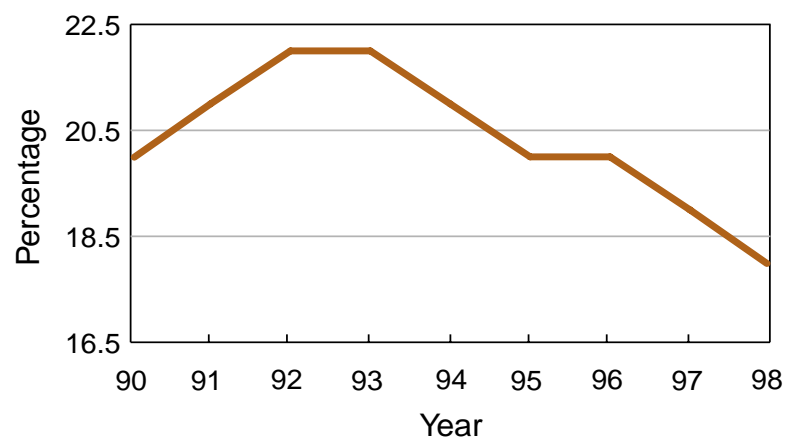

Female Victimization by Intimate Partners $\uparrow$

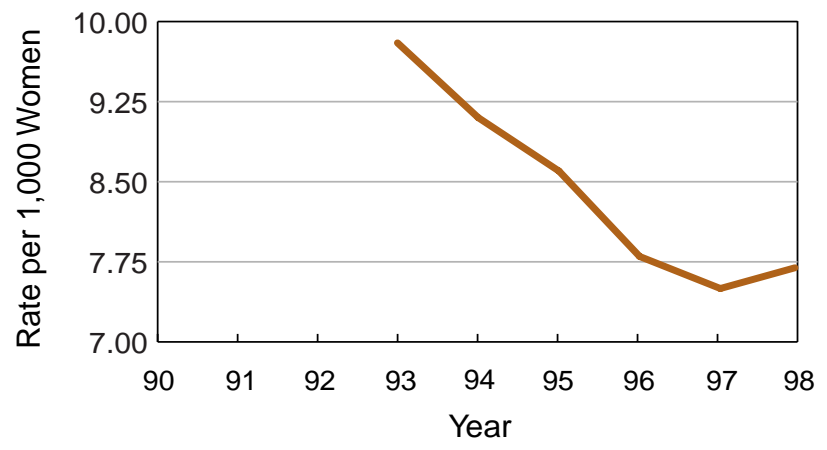

Rape Victimization $\%$

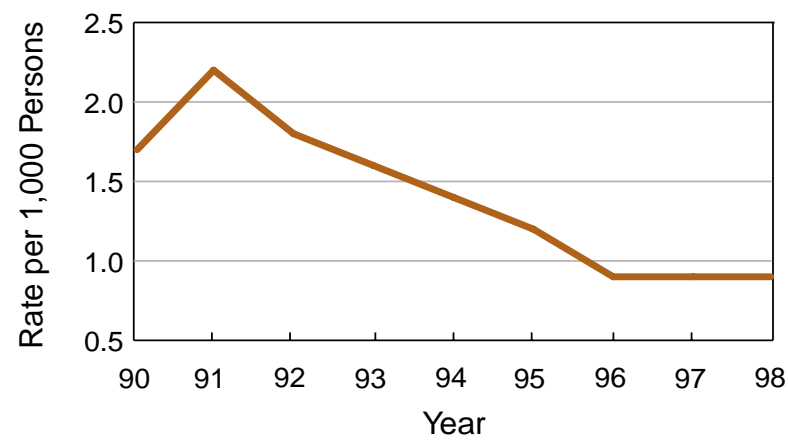

Teen Birth Rates (Females Ages 15-17)§

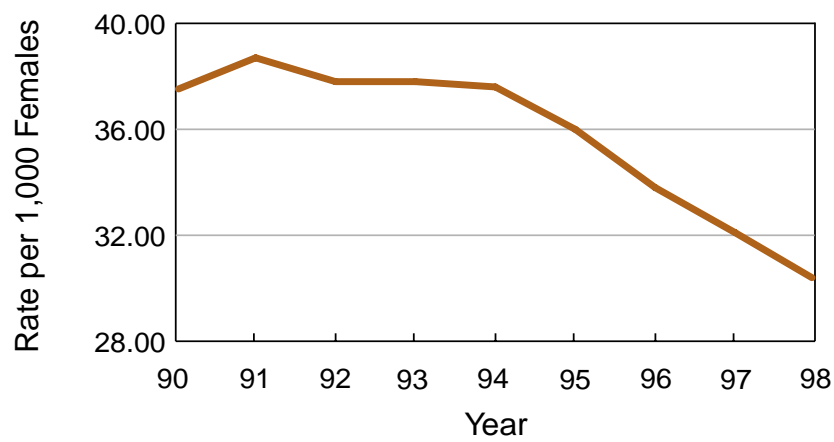

* Source: Authors' analyses of 1990-98 data (U.S. Department of Health and Human Services, 1992-2000).

$\dagger$ Source: 1993-98 NCVS data (Rennison and Welchans, 2000). Data not available for 1990, 1991, and 1992.

$\dagger$ Source: 1990-98 NCVS data (Bureau of Justice Statistics, n.d.).

$\S$ Source: 1990-98 data (Federal Interagency Forum on Child and Family Statistics, 2000).

to trends in child sexual abuse, they do not track at the State level. Using correlational procedures, no relationships were found at the State level between declines in child sexual abuse and declines in rape, violent crime, child poverty, adolescent pregnancy, and several other child-related indicators. ${ }^{5}$ In other words, the States that saw the greatest declines in child sexual abuse were not necessarily the States that saw the greatest declines in these other variables. Although the 
country is recording national declines in overall crime and general increases in child and family well-being, it is unclear how and whether these trends are related to the decline in child sexual abuse.

\section{Decline in Reporting}

While the decline in reports and substantiated cases of child sexual abuse could reflect a real decline in the problem, it is also possible that these declines are completely or partly due to factors unrelated to the actual incidence of sexual abuse. Only a subset of child sexual abuse cases are actually identified and reported to a child protective service agency each year. A number of factors could have reduced the number of reports being made to these agencies, even if the yearly incidence of sexual abuse itself had not declined.

One possibility is that reporting behaviors have changed. For example, there could be an increased reluctance to report child sexual abuse because of a so-called child abuse backlash. Some researchers who have analyzed media coverage of child sexual abuse have found a more skeptical attitude toward the topic in the 1990's (Beckett, 1996; Myers, 1994). According to these researchers, the dominant message of recent publicity about child sexual abuse has been that false allegations are frequent, that many innocent people are being unfairly stigmatized, and that professionals are being overly zealous in reporting possible cases of sexual abuse. Those concerned about a backlash point to increased activity by advocacy groups who distribute anti-CPS literature and support legislative initiatives to increase the rights of alleged perpetrators. As a result of this activity, victims and their confidants may have become more reluctant to seek help and professionals more reluctant to report their suspicions.

Another possibility is that the public and/ or professionals who are mandated to report possible cases of child sexual abuse have become less vigilant about identifying cases of sexual abuse and reporting them to CPS. There was an upsurge of public attention to this issue in the 1980'sgiven the public awareness campaigns, notable cases of sexual abuse publicized by the media, and the increased presence of prevention programs in schoolsleading to more vigilant identification and reporting of potential victims. In the 1990's, however, there may have been some decline in the prominence of this issue, resulting in reduced reports.
It would be an unfortunate occurrence if, because of decreased attention, fewer true victims were being identified. However, it could also be that the public or professionals are reporting less child sexual abuse because they are better distinguishing between actual signs of sexual abuse and signs of other problems. For example, in the 1980's, a diagnosis of urinary tract infection (UTI) in a child may, by itself, have resulted in a call to a CPS agency. However, education over the past decade has increased awareness that a UTI in a child can have many sources and that more evidence is necessary to make a report of suspected sexual abuse.

There is an additional possibility that could reduce the number of reports of child sexual abuse. Thirty years ago, when public awareness campaigns and prevention programs were initiated, many victims were identified whose experiences had previously gone unrecognized. It is likely that the upsurge in cases during the 1980's included many cases where the abuse had occurred over a long period of time or several years prior to the report. This reservoir of longer standing cases may have been reduced so that each year an increasing proportion of reports are recent cases of abuse. This might appear as a decline in total cases even if the yearly incidence of sexual abuse remains the same.

\section{Decline in Substantiation of Cases}

Additional explanations for the decline in substantiated cases of child sexual abuse include events that could be occurring after a report is made to a CPS agency. It may be that fewer reports of sexual abuse are being investigated or that fewer investigations are being substantiated. A reduction in the number of investigations of

\section{Defining Child Protective Services Terminology}

\section{Term}

Report

Screened report

Substantiated report

Indicated report

\section{Description}

A "report" is any allegation of child maltreatment that is made to a child protective services (CPS) agency from sources that include mental health personnel, medical personnel, justice system personnel, daycare providers, family members, friends and neighbors, and victims.

A report of child maltreatment is "screened in" if the report is followed by a decision to investigate. A decision to screen out a report can be made if the call is determined to be misleading or if the incident does not fall under the jurisdiction of the agency as defined by State law.

An investigation results in a "substantiated" report when the allegation of maltreatment is found to be valid and is supported by evidence under State law or policy. In different States, this disposition is also called "determined," "founded," or "true." An unsubstantiated report is not the equivalent of a false or erroneous report. States vary as to the level of evidence needed to substantiate an allegation of maltreatment. It is likely that many valid reports of child maltreatment are categorized as unsubstantiated because the required level of evidence was not met.

In addition to substantiated and unsubstantiated reports, some States allow a finding of "indicated" following an investigation. Indicated cases are typically those in which there was strong reason to suspect that the allegation of maltreatment was valid, but the agency was unable to substantiate the allegation under State law or State policy (for example, because of limited evidence or difficulty identifying the perpetrator). If the disposition of indicated is an option, the system is described as "three-tiered." States that allow only a disposition of unsubstantiated or substantiated are described as having "two-tiered" systems. When tallying total child sexual abuse cases, NCANDS combines indicated cases with substantiated cases for States with three-tiered systems. 
alleged sexual abuse could be due to changes in the type of cases CPS agencies accept as falling within their jurisdiction. More and more of these agencies may be excluding certain types of cases, such as extrafamilial child sexual abuse or abuse that involves adolescent victims or offenders. CPS agencies may also be requiring that more or better quality information be available before a report is investigated.
Informal changes in screening may also be occurring. For example, if caseloads have been increasing, CPS workers may begin screening out less serious cases or may in other ways increase the threshold for what is accepted for investigation. Some evidence suggests that such a change in screening does occur when caseloads increase (Wells, Downing, and Fluke, 1991), but it is unclear why such a change might affect child sexual abuse

\section{Figure 9: Three Patterns Representing State Changes in Substantiated Cases of Child Sexual Abuse, 1990-98}

\section{Example: Florida}

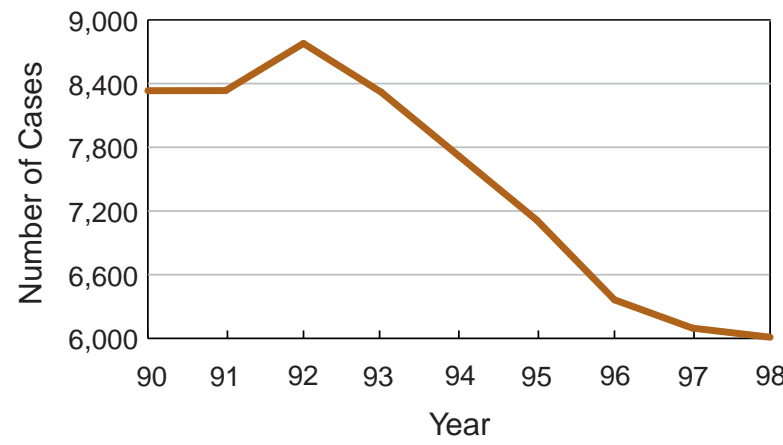

Continuous Decline:

- Twenty-six States.

- Overall decline from peak at least 25 percent.

- Three yearly declines since peak.

\section{Example: Wyoming}

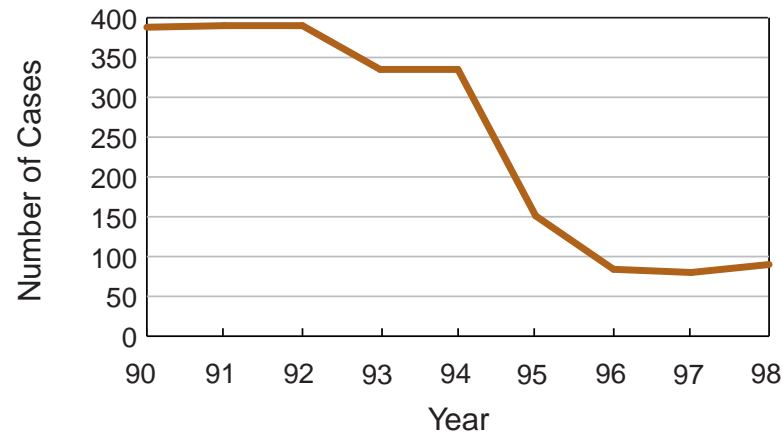

Discontinuous Decline:

- Thirteen States.

- A decrease of 33 percent or more in one year since peak.

\section{Example: North Carolina}

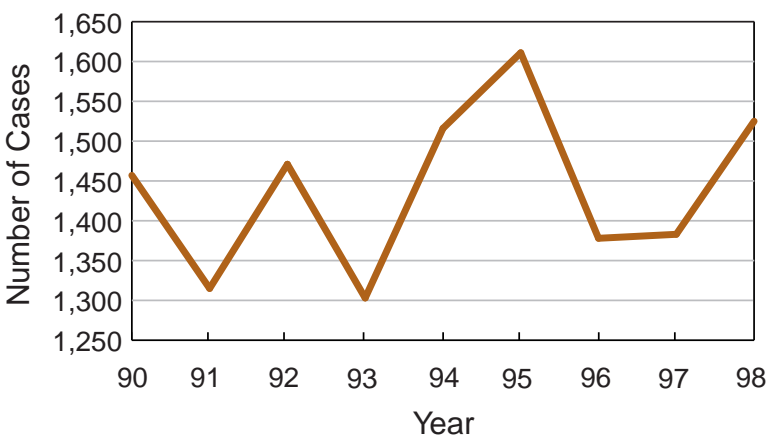

Fluctuating Change:

- Eight States.

- Overall decline from peak less than 25 percent.

- Fewer than three yearly declines since peak.

Source: Authors' analyses of 1990-98 data (U.S. Department of Health and Human Services, 1992-2000). cases in particular and not other forms of maltreatment.

Finally, there could also be changes that affect which investigations result in substantiation. Given the criticisms that they have experienced, CPS investigators may have become more conservative in the standards and criteria they use to substantiate cases. If agencies are fearful of becoming entangled in an appeals process, they may be more cautious about which cases they substantiate. Changes in investigative procedures could lead to a decline in substantiated cases. For example, many CPS agencies have added a structured decisionmaking component to their investigation procedures (English and Pecora, 1994). It is possible that with greater structure, fewer cases meet the criteria for substantiation than would have if the investigator had used his or her clinical judgment. Such changes in investigative procedures could be positive if the result is more effective and accurate judgment. More cases in which sexual abuse did not in fact occur may be getting screened out. On the other hand, if valid cases of sexual abuse are now being screened out to a greater degree as a result of changes in investigative procedures, it could mean that more children are remaining in dangerous situations.

\section{State Trend Analysis}

It appears likely that, in at least a few States, changes in policy and procedure are having a noticeable effect on the child sexual abuse trend. The authors looked more closely at child sexual abuse trends within each State with the hypothesis that if the decline in substantiated cases was the result of a policy or a programmatic change, a substantial part of the decline would occur over a period of a year or two. Three patterns were identified that depicted contrasting trends for all 47 States with available data (figure 9). These patterns were labeled "continuous decline," "discontinuous decline," and "fluctuating change." The continuous decline pattern described States that had seen a fairly substantial total decline in child sexual abuse cases (25 percent or more) over an extended period of time (at least three yearly declines since the peak year). However, if a State showed a particularly large decline (33 percent or more) occurring within a single year, it was described as showing a discontinuous decline. Finally, States that reported either a total decline of less than 25 percent or fewer than three yearly declines since their peak 


\section{Percentage Declines in Substantiated Cases of Child Sexual Abuse for States, by Pattern of Trend}

\section{Continuous Decline}

\begin{tabular}{lc} 
State & Decline \\
\hline Alaska & $43 \%$ \\
California & 28 \\
Colorado & 50 \\
Florida & 32 \\
Hawaii & 51 \\
Idaho & 46 \\
Illinois & 33 \\
Indiana & 33 \\
Iowa & 35 \\
Kentucky & 32 \\
Louisiana & 38 \\
Massachusetts* & 48 \\
Michigan & 43 \\
Minnesota & 39 \\
Nevada & 34 \\
New Jersey & 66 \\
Ohio & 22 \\
Oregon & 54 \\
Pennsylvania & 42 \\
Rhode Island & 53 \\
South Carolina & 62 \\
South Dakota & 62 \\
Tennessee & 32 \\
Texas & 42 \\
Utah & 28 \\
Vermont & 54 \\
&
\end{tabular}

Discontinuous Decline

\begin{tabular}{lc} 
State & Decline \\
\hline Arizona & $89 \%$ \\
Arkansas & 102 \\
Georgia & 68 \\
Kansas & 53 \\
Mississippi & 56 \\
Montana & 61 \\
Nebraska & 38 \\
New Hampshire & 37 \\
New Mexico & 67 \\
New York & 36 \\
Virginia & 38 \\
Wisconsin & 69 \\
Wyoming & 77
\end{tabular}

Fluctuating Change

\begin{tabular}{lc} 
State & Decline \\
\hline Alabama & $22 \%$ \\
Connecticut & 40 \\
Delaware & 0 \\
District of Columbia & 19 \\
Maine & 0 \\
Missouri & 22 \\
North Carolina & 5 \\
Oklahoma & 30
\end{tabular}

Notes: Total State decline defined by calculating change from each State's peak year through 1998. Unable to calculate decline for Maryland, North Dakota, Washington, and West Virginia because extensive data were missing.

*Percentage decline calculated from peak year through 1997.

Source: Authors' analyses of 1990-98 data (U.S. Department of Health and Human Services, 1992-2000).

were described as showing a pattern of fluctuating change. These States were labeled as fluctuating because most of them saw notable periods of decline that were then offset by years in which the number of child sexual abuse cases increased.

The table above lists the States and their total percentage decline in child sexual abuse cases for each of the three trend patterns. The discontinuous decline pattern occurred in 13 States. As hypothesized, this suggests that a policy or program change may account for a large percentage of the total decline in these States. However, the trend in the majority of States (26) followed the continuous decline pattern of a gradual decline occurring over several years. For these States, it does not appear that an abrupt policy or program change could adequately account for the decline. Instead, it is likely that the trends in these States are the result of more subtle changes. Changes in caseworkers' attitudes or a declining incidence of child sexual abuse would, for example, affect the numbers of sexual abuse cases at a more gradual rate.

It is also important to keep in mind that although changes in CPS attitudes and policy may at least partially account for the decline in substantiated cases, these changes alone clearly do not represent the entire picture. The parallel decline in reports of child sexual abuse suggests that other factors, occurring before a case even reaches a child protective agency, must also be affecting the overall decline.

\section{Implications}

Each of the potential causes of the child sexual abuse decline has important policy implications. If substantiated cases of child sexual abuse are declining because fewer children are being sexually abused, this would be a major endorsement for the decade-long mobilization of public policy in this area. It would provide encouragement for those working in the field and counter criticisms that characterize child sexual abuse prevention initiatives as naive and futile (Berrick and Gilbert, 1991; Melton, 1992). It would prompt careful attention to identifying which kinds of cases were most readily being prevented and which kinds had been most intractable.

If, by contrast, substantiated cases of child sexual abuse are declining because of changes in reporting or investigation standards, the implications for policy would depend on the source of the change and the reason for its impact on the trend. It could be that reporters of alleged child sexual abuse cases are being more judicious and accurate about what they report or that investigators are more judicious and accurate in what they substantiate. Such a finding would support the effectiveness of training and education programs directed at mandated reporters and CPS investigators. However, it could also be that intimidation, negative attitudes about CPS, or increasingly stringent screening and investigation procedures are preventing more sexually abused children from receiving intervention and assistance. This would be a problematic development and would require immediate policy intervention.

Ultimately, if intimidation is a factor in the decline, policy interventions, such as proposals to revise laws governing the liability of reporters, may be required. This scenario might also necessitate increasing and improving the training of professionals in identifying child sexual abuse so that, when confronted by a case, they feel more confident in their decision to report. If the decline is due in part to changes in investigative standards, it would be important to identify whether such changes were the result of policy decisions or whether they simply reflected idiosyncratic changes in the attitudes of investigative staff. If there have been changes in investigative policies that reduce the number of children identified as victims, it would be important to identify the basis for the changes. For example, it would be useful to know whether such changes had been rooted in research 


\section{Using Child Protective Services Administrative Data To Examine Maltreatment Trends}

The trends in reported and substantiated cases of child sexual abuse described in this Bulletin are based on data from child protective services (CPS) agencies. These government agencies are set up in each State to provide services to victims of child maltreatment. CPS agencies are typically in charge of investigating reports of maltreatment (see page 7 for definitions of CPS terminology). All States have laws that require different classes of professionals to report any suspicion of child maltreatment. Reports by these professionals or by other community members come to the agencies' attention locally or through a centralized State intake process. CPS agencies investigate those reports that seem valid and fall within their jurisdiction, evaluate the level of evidence that maltreatment has occurred, and decide whether or not to substantiate the reports. If a case is substantiated, the CPS agency manages the case by providing services, arranging foster care, overseeing reunification efforts, and, ultimately, helping to decide whether parental rights should be terminated.

CPS agencies record, with varying degrees of detail, the number of reports of child maltreatment that come through their offices each year, information about the allegations, the number of cases that are substantiated, and summaries of services provided to children. Data stored in the CPS administrative system represent only those cases of maltreatment that come to CPS attention. Many cases of child maltreatment never come to official attention at all. Furthermore, most States limit the role of CPS agencies to cases of maltreatment by caretakers. This would include investigating reports of abuse by parents and guardians, babysitters, teachers, and other individuals who share responsibility for caring for the child but not abuse by neighbors or acquaintances. CPS data, therefore, do not fully track trends in extrafamilial or noncaretaker sexual assaults on children, which are typically handled exclusively by law enforcement. Despite capturing only a certain proportion of cases, CPS data are the best source for analyzing national trends in child maltreatment because aggregate information is available on an annual basis.

There are, however, a number of limitations to interpreting administrative data from CPS agencies. One problem is that States have very different methods of tallying their statistics. Some States record reports by incident, others by family, and others by child. For example, sexual abuse of three children in one family could be counted as one or three substantiated cases, depending on the State. Furthermore, some States count as reports only investigated cases of maltreatment, while others include any allegation that comes into the system. Finally, States also vary in the level of evidence needed to substantiate a case of maltreatment. These differences make it difficult to compare data between States and require that total numbers of reports or substantiated cases be interpreted cautiously. However, because the data set collected within each State is similar from year to year, overall trends are informative. and general professional practice or had been more reactive and politically based.

It is possible that CPS is redefining its role in such a way that other agencies (such as police and mental health) are taking responsibility for cases that previously fell under the jurisdiction of CPS. If this is the case, it would be important to identify which cases are no longer being investigated or substantiated by CPS and to learn what is happening to the children involved in those cases. Are nonfamilial cases of child sexual abuse or less serious cases of child sexual abuse being more appropriately referred? Or are more cases falling through the cracks? Research will be necessary to provide clear answers to these questions.

\section{Conclusion}

While the evidence demonstrates that a dramatic decline in reports and substantiated cases of child sexual abuse has occurred, the reasons for the decline are less clear. The available data suggest that this decline is not simply explained by trends in other types of maltreatment but is instead something particularly affecting child sexual abuse cases. It could be that the observed decline is the result of a decrease in the actual incidence of child sexual abuse, a change in reporting behavior, and/or policy and program changes within CPS. Although it may be difficult to sort through the possible causes of the decline, doing so will provide a better gauge of efforts to protect children from sexual victimization.

Additional research is crucial to a better understanding of the causes of the decline in child sexual abuse. Further analysis of CPS administrative data could help determine the relationship between trends in initial reports, screened reports, and substantiated reports. Analysis of changes in the types of reporters, the ages of alleged victims, the characteristics of alleged perpetrators, and the characteristics of the abuse would provide information on the types of cases that have seen the greatest declines. Evaluation research is needed on changes in CPS policies and procedures so that the impact of these changes on child victims and their families can be better understood. Finally, the issues discussed in this Bulletin highlight the need for better justice system data about this crime, such as will be available when the National Incident-Based Reporting System becomes national in scope or as could be provided by a regularly conducted population survey concerning crimes against children.
Despite the dramatic nature of the decline in child sexual abuse cases and the importance of identifying its sources, a discussion of these issues has not yet made it to the public arena. Greater publicity has been given to other social indicators for which the declines have been less dramatic. Rates of general crime, child poverty, and teen births have declined at an equal or lesser rate than child sexual abuse, yet these declines have received more attention and have generated more discussion. This Bulletin is an attempt to direct similar attention to trends in child sexual abuse, in the hope that increased public attention will result in better assessment of the progress made to date in protecting children and ultimately will lead to improved future efforts.

\section{For Further Information}

For further information, contact:

Crimes against Children Research Center University of New Hampshire

Durham, NH 03824

603-862-1888

603-862-1122 (fax)

E-mail: lmjones@cisunix.unh.edu,

david.finkelhor@unh.edu

Internet: www.unh.edu/ccrc/ 


\section{NCANDS and the Annual Fifty State Survey}

Data from child protective services (CPS) agencies are collected, summarized, and published annually by two different organizations: the Children's Bureau and Prevent Child Abuse America.

The Children's Bureau, located within the U.S. Department of Health and Human Services' Administration for Children and Families, oversees the National Child Abuse and Neglect Data System (NCANDS). The National Center on Child Abuse and Neglect established NCANDS in response to the Child Abuse Prevention and Treatment Act (PL 93-247), which called for the creation of a coordinated, universal, national data collection program. A survey is sent to all of the States each year requesting information from State child welfare agencies on a number of variables related to child maltreatment. NCANDS collects CPS data using a twopronged approach. Aggregate data on a number of key indicators are collected through the Summary Data Component (SDC) from all States. The first published report consisted of 1990 data (U.S. Department of Health and Human Services, 1992). More extensive, case-level data are collected through the Detailed Case Data Component (DCDC). Only 20 States were able to provide data for DCDC in 1998 (U.S. Department of Health and Human Services, 2000). To best capture national trends, SDC data were used in the analyses conducted for this Bulletin.

Prevent Child Abuse America (previously the National Committee to Prevent Child Abuse) is a private, nonprofit organization that oversees national, State, and community programs directed at preventing child abuse. Through its Annual Fifty State Survey, this organization collects CPS agency data on the number and characteristics of child abuse reports and substantiations, child abuse fatalities, and changes that have occurred in child welfare services (Wang and Harding, 1999). The survey has been conducted each year since 1986 . The data collected by Prevent Child Abuse America are the only source of information on reports categorized by maltreatment type and therefore the best resource for tracking national trends in child sexual abuse reports.

One limitation of the data provided by NCANDS and the Annual Fifty State Survey is that at least a few States are missing from the summary each year. This means that the numbers of reports and substantiated cases are not true national totals. For example, NCANDS data for 1998 indicated that the total number of substantiated child sexual abuse cases was 99,278, up 1 percent from 98,339 in 1997. But the total for 1998 is based on 48 States, while the 1997 total is based on 43 States. To control for the differences in the number of States providing data, the numbers of substantiated cases for each year (1990-98) have been extrapolated to account for the total U.S. population under age 18. This brings the estimates for 1997 and 1998 to 117,000 and 103,600, respectively, an 11-percent decline over this period. Although the extrapolated numbers provide only a crude estimate of the actual number of substantiated cases, they do allow a more accurate assessment of the rate of decline in child sexual abuse cases over the years.

\section{Notes}

1. The numbers presented here are an extrapolation of data from the National Child Abuse and Neglect Data System (NCANDS) Summary Data Component (SDC). NCANDS actually reported 124,467 cases of substantiated child sexual abuse in 1992, based on 49 States (including the Virgin Islands and Puerto Rico) and 99,278 cases in 1998 , based on 48 States. These totals were extrapolated for the 50 States and the District of Columbia based on the national child population as estimated by the U.S. Census Bureau (see discussion of NCANDS and the Annual Fifty State Survey above)

2. Totals presented in the text of this Bulletin do not include data from Guam, Puerto Rico, or the Virgin Islands. Included, to the extent that the data are available or in extrapolated totals, are all 50 States and the District of Columbia. The 50 States and the District of Columbia are referred to as "States" throughout the paper. When information was available for fewer than the total possible number of 51, it is clarified in the text.

3. Prevent Child Abuse America estimates the number of reports through the following procedure: States are asked to provide the percentage of reports received by their agencies that were child sexual abuse allegations. Only 25-33 States have been able to provide these statistics each year. National reports are estimated based on the assumption that the remaining States experience similar proportions of reports by maltreatment type. The percentage of reports that are child sexual abuse allegations are averaged across the participating States. That average is used to calculate an estimate from the total number of reports received by all States. In 1998, a total of $3,154,000$ reports were made to child protective services (CPS) agencies. Twenty-eight States reported that an average of 10 percent of their reports were child sexual abuse allegations. An estimate of 315,400 reports of child sexual abuse was therefore calculated for this year. However, differences in the number of States submitting data can greatly alter the estimated reports. Wang and Harding (1999, p. 10) note that "within the 22 States providing data for both 1997 and 1998 , the percentage of child sexual abuse cases remains consistent at 8 percent." If an 8-percent average were used instead of 10 percent, the resulting estimate of child sexual abuse reports would be 252,320 . This is still an increase from 1997, but a more modest 13-percent increase compared with the reported 41-percent increase. This example highlights the need for increased reliability and consistency in CPS administrative data so that the pattern of child maltreatment can be interpreted with greater confidence.

4. Prevent Child Abuse America reported that in 1998, the latest year for which data are available, the total number of maltreatment reports decreased slightly from the previous year for the first time ever (Wang and Harding, 1999).

5. For each State, the percent change from 1992 to 1998 was calculated for the following variables: child sexual abuse, forcible rape (UCR data), aggravated assault (UCR data), child poverty, high school dropout, teen pregnancy, single parent households, teen suicide, and parent unemployment. Correlations between child sexual abuse and all other variables were small $(r<0.12)$ and nonsignificant.

\section{References}

American Association for the Protection of Children. 1988. Highlights of Official Child Neglect and Abuse Reporting-1986. Denver, CO: American Humane Association.

Beck, A., Gilliard, D., Greenfeld, L., Harlow, C., Hester, T., Jankowski, L., Snell, T., Stephen, J., and Morton, D. 1993. Survey of State Prison Inmates, 1991. Washington, DC: U.S. Department of Justice, Office of Justice Programs, Bureau of Justice Statistics.

Beckett, K. 1996. Culture and politics of signification: The case of child sexual abuse. Social Problems 43:57-75.

Berrick, J.D., and Gilbert, N. 1991. With the Best of Intentions: The Child Sexual Abuse Prevention Movement. New York, NY: Guilford Press.

Boyer, D., and Fine, D. 1992. Sexual abuse as a factor in adolescent pregnancy and child maltreatment. Family Planning Perspective 24(1): 4-11.

Bureau of Justice Statistics. n.d. National Crime Victimization Survey Crime Trends, 1973-98. Adjusted Victimization Rates. Retrieved August 13, 2000, from the Web: www.ojp.usdoj.gov/bjs/.

Elders, M.J., and Albert, A.E. 1998. Adolescent pregnancy and sexual abuse. Journal of the American Medical Association 280(7):648-650. 
Office of Justice Programs

Washington, DC 20531

Official Business

Penalty for Private Use $\$ 300$

English, D.J., and Pecora, P.J. 1994. Risk assessment as a practice method in child protective services. Child Welfare 73(5):451-473.

Federal Interagency Forum on Child and Family Statistics. 2000. America's Children: Key National Indicators of Well-Being, 2000. Washington, DC: U.S. Government Printing Office.

Finkelhor, D., and Dziuba-Leatherman, J. 1995. Victimization prevention programs: A national survey of children's exposure and reactions. Child Abuse \& Neglect 19(2):129-139.

Finn, P. 1997. Sex Offender Community Notification. Washington, DC: U.S. Department of Justice, Office of Justice Programs, National Institute of Justice.

Freeman-Longo, R.E., Bird, S., Stevenson, W.F., and Fiske, J.A. 1994. Nationwide Survey of Juvenile and Adult Sex Offender Treatment Programs and Models. Orwell, VT: The Safer Society Program.

Melton, G.B. 1992. The improbability of prevention of sexual abuse. In Child Abuse Prevention, edited by D. Willis, E. Holden, and M. Rosenberg. New York, NY: Wiley.

Myers, J.B. 1994. The Backlash: Child Protection Under Fire. Thousand Oaks, CA: Sage Publications.

Prevent Child Abuse America. 1987-98. Current Trends In Child Abuse Reporting and Fatalities: The Results of the Annual Fifty State Survey. Washington, DC: U.S. Department of Justice, Office of Justice Programs, National Institute of Justice.
Rennison, C.M., and Welchans, S. 2000. Intimate Partner Violence. BJS Special Report. Washington, DC: U.S. Department of Justice, Office of Justice Programs, Bureau of Justice Statistics.

Sedlak, A.J., and Broadhurst, D.D. 1996. The Third National Incidence Study of Child Abuse and Neglect (NIS-3). Washington, DC: U.S. Department of Health and Human Services.

U.S. Department of Health and Human Services, National Center on Child Abuse and Neglect. 1992-2000. Child Maltreatment 1990-1998: Reports From the States to the National Child Abuse and Neglect Data System. Washington, DC: U.S. Government Printing Office.

Wang, C.T., and Daro, D. 1998. Current Trends in Child Abuse Reporting and Fatalities: The Results of the 1997 Annual Fifty State Survey. Chicago, IL: The National Committee to Prevent Child Abuse.

Wang, C.T., and Harding, K. 1999. Current Trends in Child Abuse Reporting and Fatalities: The Results of the 1998 Annual Fifty State Survey. Chicago, IL: Prevent Child Abuse America.

\section{Acknowledgments}

This Bulletin was prepared by Lisa M. Jones, Ph.D., Research Fellow, Crimes against Children Research Center, University of New Hampshire; and David Finkelhor, Ph.D., Professor of Sociology, and Director, Crimes against Children Research Center, University of New Hampshire.
Wells, S.J., Downing, J., and Fluke, J. 1991. Responding to reports of child abuse and neglect. Child and Youth Services 15(2):63-72.

This Bulletin was prepared under grant number 98-JN-FX-0012 from the Office of Juvenile Justice and Delinquency Prevention, U.S. Department of Justice.

Points of view or opinions expressed in this document are those of the author(s) and do not necessarily represent the official position or policies of OJJDP or the U.S. Department of Justice.

The Office of Juvenile Justice and Delinquency Prevention is a component of the Office of Justice Programs, which also includes the Bureau of Justice Assistance, the Bureau of Justice Statistics, the National Institute of Justice, and the Office for Victims of Crime. 